\title{
COMUNICAÇÃO ORGANIZACIONAL COMO ALIADA NA GESTÃO ESTRATÉGICA DOS STAKEHOLDERS
}

\section{ORGANIZATIONAL COMMUNICATION AS ALLIED IN STAKEHOLDER STRATEGIC MANAGEMENT}

\author{
Manoel Henrique Ribeiro Castro* \\ e-mail: manoel_400@hotmail.com \\ Luciana Nery de Oliveira ${ }^{* *}$, ***.**** \\ e-mail: luciananery@hotmail.com \\ * Universidade do Estado da Bahia, Salvador, BA - Brasil \\ ** Universidade Estadual do Sudoeste da Bahia, Vitória da Conquista, BA -Brasil \\ *** Faculdade Sudoeste, Vitória da Conquista, BA - Brasil \\ **** UniFG Centro Universitário Guanambi, Guanambi, BA - Brasil
}

\section{Resumo}

No cenário contemporâneo onde a concorrência global e as constantes crises exigem cada vez mais estratégias de diferencial competitivo, a comunicação revela-se como uma das mais eficazes ferramentas na evolução das organizações. Para melhor se comunicar com os públicos de interesse - stakeholders - as empresas/organizações precisam identificar e elaborar um plano com estratégias, mensagens e canais adequados a cada público de interesse. A presente pesquisa visa conhecer as estratégias e ferramentas utilizadas pelas organizações no âmbito da comunicação com seus grupos de interesses, para isso todo o trabalho foi feito mediante pesquisas bibliográficas, entendimentos já difundidos e consagrados na literatura. As pesquisas sobre os conceitos de comunicação e também das abordagens da teoria dos stakeholders demonstram que, com esses conhecimentos, pessoas e organizações podem explorar cada vez mais e melhor a comunicação com seus públicos de interesse, bem como melhorar os relacionamentos com os mesmos.

Palavras-chave: Comunicação Organizacional. Stakeholders. Estratégia.

\begin{abstract}
In the contemporary scenario where global competition and constant crises increasingly demand competitive differentiation strategies, communication proves to be one of the most effective tools in the evolution of organizations. To better communicate with stakeholders - companies - organizations need to identify and develop a plan with strategies, messages and channels that are appropriate for each audience. This research aims to know the strategies and tools used by organizations in the context of communication with their interest groups, for all this work was done through bibliographical research, understandings already widespread and established in the literature. Research into communication concepts as well as stakeholder theory approaches shows that with this knowledge, people and organizations can increasingly and better explore communication with their stakeholders, as well as improve relationships with them.
\end{abstract}

Keywords: Organizational Communication. Stakeholders. Strategy. 


\section{INTRODUÇÃO}

A comunicação humana possui relevante papel nas organizações, sua utilização não deve ser apenas satisfatória, mas também deve ser produtiva e capaz de gerar resultados tangíveis e intangíveis tanto para a própria organização quanto para os indivíduos.

Berlo (2003) diz que uma organização só existe por meio da comunicação, e esta para Zarifian (2008) é e continuará a ser uma questão difícil, pois diferentes e contraditórias formas de comunicação existem na empresa, e é nesse contexto que é verificada a importância desse elemento nas organizações. Apesar de ser uma questão difícil, a busca pela comunicação eficaz deve ser um dos principais objetivos das organizações, para isso ela deve ser direcionada a todos os stakeholders ou públicos de interesses.

Este estudo considera que os stakeholders ou públicos de interesse das organizações são formados por: proprietários, diretores, funcionários, concorrentes, clientes, sindicatos, governo, imprensa entre ouros grupos, essa característica faz com que a maneira de se comunicar seja também diferenciada, portanto, as estratégias para a comunicação com cada um deles devem ser elaboradas minuciosamente e com muita cautela, pois, uma comunicação mal elaborada pode colocar em risco até a existência da organização.

Assim, reunir informações adicionais para o estudo do tema stakeholders, faz-se pertinente na contemporaneidade, seja para dar auxilio às organizações na implementação de estratégias para uma melhor comunicação com os grupos de interesse, ou para garantir bons relacionamentos com esses públicos.

É preciso saber comunicar-se, seja com os stakeholders internos ou externos, diante desse cenário é feita tal indagação: quais os elementos da comunicação organizacional contribuem para a gestão estratégica dos stakeholders?

Para responder tal questionamento parte-se como objetivo geral desse estudo conhecer os elementos estratégicos utilizados pelas organizações no âmbito da comunicação com seus grupos de interesses, para isso é necessário percorrer um caminho através de alguns objetivos específicos tais como: apresentar os conceitos de comunicação organizacional, concatenar abordagens e ideias no que tange a comunicação nas organizações, abordar a teoria da gestão de stakeholders e apresentar elementos estratégicos para uma melhor comunicação entre as organizações e seus públicos de interesse.

O referencial teórico do artigo está estruturado em comunicação e seu conceito transversal, comunicação organizacional: dos conceitos às barreiras, gestão estratégica dos stakeholders, a comunicação como estratégia organizacional e comunicação estratégica com os stakeholders. Com relação aos procedimentos metodológicos possui caráter qualitativo e visa buscar na literatura conhecida a respeito dos temas comunicação nas organizações e teoria dos stakeholders, a compreensão acerca das discussões existentes, objetivando, a partir da reflexão posta construir novos conhecimentos acerca do mesmo. 


\section{REFERENCIAL TEORICO}

\subsection{Comunicação: um conceito transversal}

A comunicação é um sistema de grande complexidade, prova disso é seu caráter multidisciplinar, passando por diversas áreas do conhecimento humano, principalmente nos campos das ciências sociais e humanas. "Ao analisar o fenômeno comunicativo, cada ciência e corrente filosófica utiliza a sua própria perspectiva, a sua própria terminologia, os seus conceitos específicos". (MARQUES DE MELO, 1975, p.31).

Assinala-se, portanto, que a comunicação é vista sob diversos ângulos, não sendo exclusividade de nenhum área de conhecimento, sua analise deve considerar o contexto onde está inserida, na área da educação, por exemplo, sua abordagem difere-se do campo da administração, já este não é igual o da abordagem linguística ou mesmo da psicologia.

A palavra "comunicar" vem do latim "communicare" com a significação de "pôr em comum". Comunicação é convivência; está na raiz de comunidade, agrupamento caracterizado por forte coesão, baseada no consenso espontâneo dos indivíduos. Consenso quer dizer acordo, consentimento, e essa acepção supõem a existência de um fator decisivo na Comunicação humana: a compreensão que ela exige, para que se possam colocar, em "comum", ideias, imagens e experiências. (...) Seu grande objetivo é o entendimento entre os homens. Para que exista entendimento é necessário que se compreendam mutuamente indivíduos que se comunicam. (PENTEADO, 1982, p.01).

O conceito de Penteado evidencia que a comunicação possui como elemento chave o entendimento entre as pessoas e a compreensão do que se é transmitido, só assim a convivência social tem sentido. A "comunicação é o ato de comunicar-se, emitir, transmitir e receber mensagens através de métodos convencionados". (FERREIRA, 1986, p.443). Sendo assim o processo de comunicação é basicamente constituído pelos seguintes elementos: emissor, mensagem, canal e receptor.

Para Pereira e Herschmann (2002) o campo da comunicação como um todo, pode ser compreendido como um espaço onde se constrói e circula sentidos e informações, sendo, portanto, 
um construto de realidades simbólicas, onde se desempenha esse papel-chave fascinante de constituir-se em ambiente por excelência de construção da realidade contemporânea.

Sant'Anna, Junior e Garcia (2015), afirmam que o termo comunicação é amplo e que tudo comunica, e, por isso é uma das matérias do estudo do comportamento humano mais interessante, pois sem a mesma não existiriam os grupos e as sociedades. "A comunicação é o processo pelo qual conduzimos nossas vidas. Assim que dois ou mais indivíduos se reúnem, há a necessidade de comunicação entre eles, algum modo de facilitar o entendimento do que cada um quer e precisa daquela situação" (BOWDITCH E BUONO, 2004, p.80).

Já Robbins, Judge e Sobral (2011) tem a comunicação como um sistema de funções básicas sendo elas: controle, motivação, expressão emocional e informação, que de acordo com Bowditch e Buono (1992, p.82) "tem diversas finalidades diferentes, e as informações são trocadas por muitas razões, nem todas elas dirigidas a uma tarefa especifica".

Diante desses diversos conceitos, verifica-se, portanto que o entendimento é a finalidade da comunicação tanto da interpessoal (troca de informações entre duas pessoas) quanto da organizacional (que ocorre dentro da organização seja publica ou privada).

Diante do exposto, verifica-se que a comunicação perpassa por diversas abordagens e possui vários componentes, neste trabalho o cerne dele é a comunicação no ambiente organizacional, devido a sua relevância para a vida em sociedade.

\subsection{Comunicação nas organizações: dos conceitos e importância às barreiras}

Comunicação empresarial, corporativa, estratégica e organizacional, muitas nomenclaturas, mas a mesma definição em linhas gerais, todas elas nascem nas organizações sejam privadas ou publicas e seu objetivo é a interação com os públicos de interesse.

Assim entendemos comunicação empresarial, ou comunicação organizacional como: conjunto integrado de ações, estratégias, planos, políticas e produtos planejados e desenvolvidos por uma organização para estabelecer a relação permanente e sistemática com todos os seus públicos de interesse. (BUENO 2009, p.4).

Segundo Leavitt (1972) a comunicação é um canal que influencia e permite trocas, sendo necessária sua discussão pela criticidade que a mesma possui no contexto organizacional. Logo, falar sobre comunicação é urgente, sobretudo no contexto organizacional, onde o processo de trocas é intenso e continuo. 
Já para Chiavenato (2014) a comunicação permeia todas as funções administrativas, constituindo uma parte essencial em cada atividade administrativa, é impossível planejar, dirigir, organizar e controlar sem exercer a comunicação. Sob essa perspectiva, sua relevância em todos os processos organizacionais é indiscutível, ao planejar as ações, os superiores devem informar aos subordinados as mesmas, bem como ao organizar a estrutura e controlar seus resultados, mas principalmente ao dirigir pessoas, a comunicação sempre será necessária.

Na perspectiva empresarial, de acordo com Carvalho e Serafim (1995) a comunicação tem como característica a transmissão de ideias, com finalidade de integrar por completo um grupo de trabalho. Observa-se que nesse conceito também o objetivo é reunir esforços, é dirigir o trabalho dentro das organizações.

Quando se fala em comunicação empresarial de acordo com Nassar e Figueiredo (1995) ela não pode ser considerada apenas uma definição de dicionário, ou seja, simplesmente como um conjunto de métodos e técnicas de comunicação dentro da empresa dirigida ao público interno (funcionários) e ao público externo (clientes, fornecedores, consumidores, etc.), de modo a satisfazer os mesmos.

A comunicação empresarial moderna e excelente tem entre seus principais atributos: o monitoramento dos ambientes nos quais a empresa se insere, para detectar as ameaças e as oportunidades simbólicas; a seleção de informações e as oportunidades simbólicas; a seleção de informações importantes para a tomada de decisão da gestão; o mapeamento dos públicos estratégicos, a velocidade nas emissões e respostas; a formatação impecável e adequada de mensagens; a seleção de mídias que cheguem aos públicos estratégicos; a habilitação, em comunicação de todas as pessoas da organização; as pesquisas; o planejamento e a operação de orçamentos. (NASSAR, 2006, p.122).

Nesse contexto, toda organização necessita de uma comunicação eficaz, nenhuma atividade pode ser bem realizada se não houver uma comunicação adequada. Hitt, Miller e Colella (2007) afirmam que apesar de ser difícil conquistar a eficácia na comunicação, ela deve ser buscada com muito afinco, pois é de grande relevância para o melhoramento da estrutura organizacional. Sendo assim, os vários tipos de comunicação devem cumprir sua missão de informar e transmitir ideias com custos ou despesas baixas e realizando os objetivos organizacionais, sendo assim eficiente e eficaz.

Maximiano (2004) também corrobora e complementa esse pensamento ao afirmar que a comunicação organizacional depende da qualidade da comunicação pessoal, só assim os processos organizacionais alcançarão a eficácia.

Como visto, o processo de comunicação visa a transmissão de ideias de modo efetivo, mas nem sempre isso acontece, ocorrem diversas interferências nesse caminho, elas são chamadas de 
barreiras ou ruídos. De acordo com França (2014, p. 144) "as barreiras para a comunicação eficaz referem-se aos fatores que dificultam a comunicação por meio da distorção das mensagens e dos ruídos e obstáculos no processo de comunicação", sendo que a busca pela comunicação eficaz nas organizações se justifica pelas inúmeras falhas existentes nesse processo.

Um dos elementos de entrave no processo de comunicação nas organizações é apresentado por Matos (1980) para ele o boato é um grande obstáculo para as empresas, pois o mesmo pode destruir os grupos, não importando se os boatos são criados intencionalmente ou espontaneamente, de toda forma a Administração da organização deve oferecer respostas para combater esse problema.

Hampton (1992) também aponta outros obstáculos à compreensão sendo eles: falta de clareza, varias fontes concorrentes, mensagens não desejadas, distorção por intermediários, canais sobrecarregados, prioridades em choque, desatenção, avaliação prematura, resposta a fatores imateriais, preparar a própria resposta em vez de ouvir e má interpretação.

Outras barreiras são descritas por Robbins, Judge e Sobral (2011) da seguinte forma:

- Filtragem, caracterizada pela manipulação da informação, quando se fala o que o chefe quer ouvir por exemplo.

- Percepção seletiva, quando o receptor vê e escuta seletivamente, de acordo com necessidades, motivações, experiências, históricos e características pessoais.

- Sobrecarga de informações são inúmeras informações em que as pessoas tem que lidar, diante disso, surge a sobrecarga, caracterizada pela seleção, ignorância ou esquecimento dessas informações.

- Emoções, estados emocionais como euforia ou depressão também propiciam a comunicação ineficaz.

- Idioma, mesmo utilizando a mesma língua, as palavras podem ter significados diferentes a depender de fatores como idade, região e contexto cultural.

- Silencio ou falta de comunicação é a ausência de informação.

- Medo da comunicação ou ansiedade social, de acordo com vários estudos é muito comum pessoas sofrerem disso, e isso tem graves consequências, pois impossibilita o desenvolvimento da comunicação oral ou escrita.

- Ruído é qualquer coisa que estraga a comunicação ou mensagem.

- Falta de capacidade de ouvir, muito frequente na comunicação interpessoal e organizacional, caracteriza-se pelo receptor não saber ouvir, o que é um grande entrave no processo de comunicação.

Todas as barreiras apresentadas bem como outras existentes fazem com que a organização tenha sua imagem afetada perante seus stakeholders. A comunicação prejudicada tem efeitos negativos muitas vezes irreversíveis, para toda e qualquer organização.

\subsection{A Comunicação como Estratégia Organizacional}


Após a globalização e a revolução tecnológica, as organizações precisaram se reinventar para acompanhar tamanhas mudanças, surgindo então a estratégia como fator de destaque, de acordo com Chiavenato e Sapiro (2010) o elemento estratégia é justamente isso um movimento que é sempre de mudança e transformação.

O termo estratégia banalizou-se muito na atualidade, nem sempre o que é tido como estratégia é de fato uma, sua difícil compreensão se deve ao fato de sua abrangente definição. Para Chandler (1962, p.13, apud OLIVEIRA, 2007, p.5) "estratégia é a determinação de metas básicas a longo prazo e dos objetivos de uma empresa e a adoção das linhas de ação e aplicação dos recursos necessários para alcançar essas metas.”.

Já para Maximiano (2004, p.128), “as estratégias das organizações são respostas aos desafios e oportunidades do ambiente dos sistemas internos", definição semelhante com a de Oliveira (2007, p.5), "uma situação pode ser considerada como estratégica quando existe interligação entre os aspectos internos e externos da empresa.". A perspectiva apresentada por esses autores remetem ao ambiente organizacional, é nele que tudo acontece, e é para ele que tudo está voltado.

Tais conceitos apesar de certas diferenças trazem algumas palavras-chaves mesmo que implicitamente no conceito de estratégia, são elas: longo prazo, objetivos e metas, e ambiente externo e interno.

Do ponto de vista de Cahen (1990) a comunicação é como uma atividade estratégica e sistêmica, pois está ligada ao planejamento estratégico organizacional, tendo como objetivos a criação, manutenção ou alteração da imagem da organização perante seu publico prioritário.

Os processos de comunicação nas empresas são estabelecidos entre pessoas situadas nos ambientes interno e externo e envolvem uma infinidade de assuntos. São dirigidos para comunicar uma decisão, informar um acontecimento, anunciar produtos, atender a solicitação dos clientes, fazer encomendas para os fornecedores, efetuar transições financeiras com os bancos etc. (BEUREN, 1999, apud SCHULER, 2004, p.28.).

Marchiori (2008) destaca que para o processo de comunicação ser estratégico é preciso que ele propicie mudanças de comportamento, e não apenas seja um meio pra informar sobre o que acontece nas organizações.

Destarte todo o sistema comunicacional, sua finalidade e utilização é um item estratégico de grande valor para as organizações, principalmente considerando seus relacionamentos com os públicos de interesses. 


\section{B ConveA}

\subsection{Gestão Estratégica dos Stakeholders}

Destacada como uma teoria em 1963 por Edward Freeman, a Gestão dos Stakeholders tem como objeto de estudo a interação das organizações com o ambiente e como objetivo definir quais são os públicos de interesse de uma organização, considerando, assim que todos os grupos de pessoas direta ou indiretamente ligados à mesma possam influenciar ou ser influenciados por suas ações, portanto devem ser considerados em uma possível tomada de decisão.

A teoria dos stakeholders amplia o foco da organização, que antes era satisfazer o acionista e passa a ser satisfazer seus públicos de interesse estratégicos, como clientes, funcionários, imprensa, parceiros, fornecedores, concorrentes, sindicatos e a comunidade local. (ROCHA e GOLDSCHMIDT 2010, p.6).

Segundo Orth (2009) os stakeholders são pessoas, grupos de pessoas ou entidades que participam ou influenciam o projeto, de maneira direta ou indireta, com interesses em sua evolução ou quando são afetadas por seus resultados de alguma maneira, sendo, portanto uma rede de relacionamento, não necessariamente tendo interesses econômicos.

Hitt, Ireland e Hoskisson (2008, p.19) afirmam: “Stakeholders são pessoas e/ou grupos que podem afetar e são afetados pelos resultados estratégicos obtidos e que tem reivindicações aplicáveis no tocante ao desempenho da empresa”.

Para Williams (2017, p.83) "Stakeholders são pessoas ou grupos com um interesse legitimo em uma empresa. Como são afetados pelas operações da organização, os stakeholders tem interesses nelas". Dessa forma há a necessidade de satisfazer e bem tratar os mesmos.

Isso significa que a organização deve atender aos mínimos interesses ou necessidades de todos os stakeholders, os quais devem ser atendidos através das suas ações. Caso contrario, eles podem decidir retirar seu apoio da organização e oferecê-lo a outra. (CHIAVENATO e SAPIRO 2009, p.306).

O objetivo da Teoria dos Stakeholders é mostrar como as organizações devem buscar manter uma interação saudável com os mesmos, ela é muito similar com a abordagem sistêmica da administração, onde a interação e o relacionamento com o ambiente externo têm tanto valor quanto com o ambiente interno.

Modelo de stakeholders uma teoria de responsabilidade corporativa que sustenta que a responsabilidade mais importante da direção, a sobrevivência de longo prazo, 
é alcançada pela satisfação das partes interessadas na corporação, denominadas stakeholders. (WILLIAMS 2017, p.83)

A busca pelo equilíbrio no relacionamento com os stakeholders faz com que as organizações invistam em estratégias na identificação, classificação e engajamento dos mesmos.

A partir das ideias de Harrison, segundo as autoras Rocha e Goldschmidt (2010) a analise dos stakeholders se dá também através da identificação dos interesses e do poder que os stakeholders possuem sobre a empresa, classificam-se os interesses nos stakeholders em três tipos: o de propriedade, interesse econômico e interesse social, já o poder é referenciado pelos grupos: formal, econômico e politico.

A partir daí a organização analisa o ambiente externo e interno e classificam as organizações e empresas que detêm interesse e poder sob a mesma, já o engajamento, refere-se a capacidade que a organização possui tanto em se fazer compreendida como em compreender o que os públicos de interesse desejam, é um caminho de resposta dupla, onde as organizações tem tanta responsabilidade como os stakeholders.

\subsection{Comunicação Estratégica com os Stakeholders}

Para fins desta pesquisa, foi traçado um escopo das principais ferramentas utilizadas pelas organizações cuja aplicabilidade se dá nos campos da comunicação estratégica com os stakeholders.

O planejamento estratégico de comunicação define o papel que esta arena desempenhará no processo mercadológico e que tipo de relação será construída entre marca e seus públicos-alvo. Tem a marca como ponto de partida, entendendose sua estratégia, seu posicionamento, o ambiente onde está inserida, seus concorrentes e stakeholders, e aqui, com compreensível cuidado, o consumidor final. Considera também a integração e sinergia das diferentes ferramentas de comunicação que transmitirão o mesmo conceito. (ROCHA e GOLDSCHIMIDT, 2010, p.230).

Toda organização ou empresa ao se comunicar com seus públicos de interesses almejam a formação de uma boa imagem perante eles, isso é algo relevante, como já visto uma comunicação com barreiras, pode ser muito prejudicial. 
Rocha e Goldschimidt (2010) afirmam que a produção da comunicação com stakeholders está interligada com o contexto, objetivos e maneira como as organizações se relacionam com os públicos de interesses.

A estratégia de comunicação consiste no plano da empresa para transmitir as notícias para seus públicos. A estratégia define quem são esses públicos, por que é importante comunicar- -se com eles, quando e onde a comunicação deve acontecer, quem é o responsável pelas comunicações, o que deve ser dito e qual o vínculo com as metas comerciais. (CORRADO, 1994, p. 34).

É necessário estabelecer um planejamento de utilização da comunicação, de maneira segmentada, onde a informação deve ser direcionada para cada publico de interesse. Kaplan e Norton (1997) assinalam que um programa amplo de comunicação deve está voltado para o alinhamento estratégico das organizações, e que o mesmo deve ter inicio com a resposta de algumas perguntas, tais como: quais os objetivos da estratégia de comunicação? quais são os públicos-alvo da organização? qual a principal mensagem para cada publico? quais os meios de comunicação adequados para cada público?

Como visto o planejamento estratégico de comunicação com os stakeholders é um instrumento construído que reflete toda a identidade organizacional, sua visão, missão, valores e objetivos, sua formulação é o primeiro passo no gerenciamento comunicacional, é a partir dele que são estabelecidas outras ferramentas e meios para se comunicar.

O plano de comunicação integrada fornece a orientação de como apresentar o estudo, as conclusões e as estratégias definidas pelo trabalho de planejamento. É o momento em que o planejamento realizado é apresentado e tem como objetivo fornecer a orientação estratégica e tática para a comunicação. (VASCONCELOS, 2009, p.129).

Tavares (2009) também aponta o plano de comunicação como uma ferramenta estratégica onde os objetivos, metas, estratégias de comunicação, planos de ação, controle e avaliação e investimento são avaliados através de indicadores e de relatórios como o briefing que nada mais é do que o resumo de informações coletadas na organização com o intuito de transmitir informações aos diversos públicos de interesses, tudo isso faz do plano de comunicação uma poderosa ferramenta nas organizações.

Ainda no contexto do planejamento e plano é relevante apresentar a Matriz Wave que é descrita por Rocha e Goldschmidt (2010) como uma matriz que serve para organização e visualização das ações de comunicação para cada stakeholder, sua utilização é muito simples e 
fácil, o conceito estratégico é aquilo que é indicado na identidade organizacional, na estratégia da organização, já o termo umbrella indica a ação capaz de suportar todo o plano, é o que interliga as demais ações.

Figura 1: Esquematização grafica da Matriz Wave

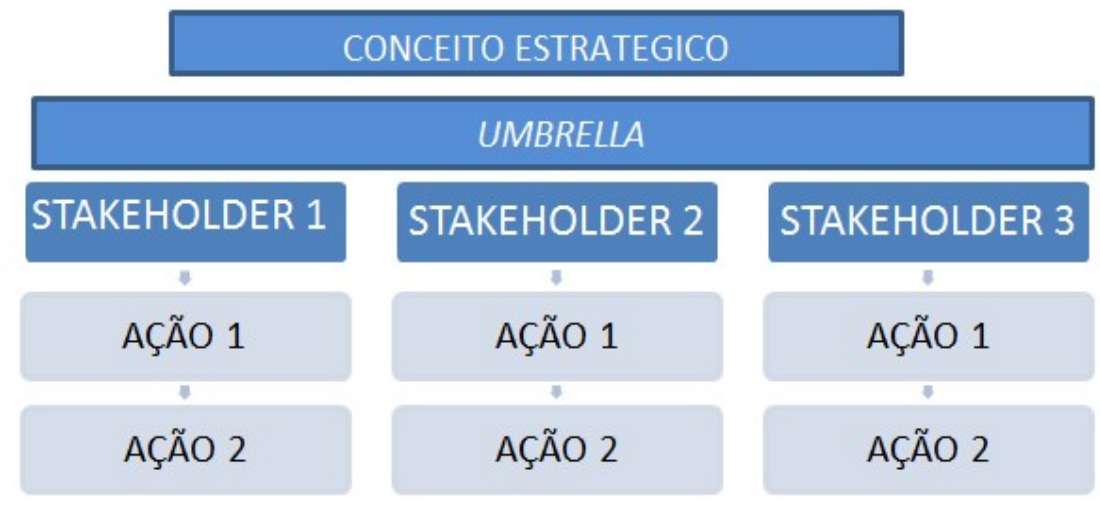

Fonte: Elaborado pelo autor inspirado em Rocha e Goldschmidt (2010)

Ao construir a matriz acima, é importante levar em consideração a relação existente entre os stakeholders e as ações voltadas para ele, de maneira exemplificativa, o conceito estratégico é elaborado no planejamento estratégico, já o umbrella é uma ação genérica como utilização de mídias sociais, a partir daí para cada stakeholder é descrito uma ação, o stakeholder 1 que pode ser o publico interno pode ser uma mídia social mais corporativa, já o stakeholder 2, clientes pode ser um outro tipo de mídia social, e daí por seguinte para cada stakeholder uma ação diferente.

Após a fase do planejamento são implementadas diversas ferramentas na comunicação com os públicos de interesse tanto interno quanto externo, utiliza-se canais de comunicação, que são o meio para fluir a mensagem do emissor ao receptor, as organizações dispõem de canais formais e informais de comunicação, sendo os mais utilizados segundo Robbins, Judge e Sobral (2011): relatórios e boletins formais, discursos gravados, memorandos, cartas, e-mails, conversas eletrônicas, videoconferências entre outros.

Outro elemento muito pertinente na comunicação é a negociação, necessária para o relacionamento com os grupos de stakeholders como sindicatos, fornecedores e trabalhadores, sendo de suma importância dominar tal habilidade.

Para Gil (2001), a negociação não deve ser vista de maneira pejorativa, mas sim como a procura da regulação das divergências, podendo ser visto como um jogo estratégico entre o conflito e a cooperação, a mesma possui etapas que vão do planejamento, definição dos objetivos, determinação da margem de negociação ate a preparação física e psicológica do negociador.

O perfil de um negociador necessário para a organização é assim posto: 
O negociador deve reunir dotes específicos, que o tornem confiável e idôneo para ambas as partes. Além do domínio das matérias colocadas em pauta, do conhecimento que terá do sindicato: seus dirigentes, seu potencial e sua verdadeira força[...] Deve ser respeitoso, sem incorrer em excessos de formalidade; objetivo e preciso na argumentação, mantendo, todavia, um clima de permanente cordialidade e deixando à vontade seus interlocutores. (PAZZIANOTTO, 1995, p. 38-39.).

Já para os stakeholders internos, surge no final do século XIX, uma nova ferramenta estratégica o endomarketing, que é o alinhamento das políticas de marketing com a de gestão de pessoas. Para Pimenta (2004) o endomarketing gera ações da área de marketing para o publico interno destacando a importância do funcionário no processo produtivo e o respeito como ser humano, com potencialidades e dificuldades.

O endomarketing é uma abordagem que visa dar humanização à comunicação no ambiente de trabalho, ela possui objetivos e atividades a serem desenvolvidas.

Um programa de endomarketing só será bem-sucedido se contar com total apoio da alta administração, fizer parte da estratégia global da organização, tiver apoio de uma estrutura organizacional adequada e envolver todas as categorias de empregados. (FRANÇA, 2014, p.157).

O endomarketing, portanto possui grande relevância no contexto organizacional, os públicos internos são os primeiros "clientes" das organizações, eles devem entender muito bem o que se passa nela para em seguida conseguir transmitir tudo que a organização deseja.

O endomarketing consiste em ações de marketing dirigidas ao público interno da empresa ou organização. Sua finalidade é promover entre os funcionários e os departamentos os valores destinados a servir cliente ou, dependendo do caso, o consumidor. Essa noção de cliente, por sua vez, transfere-se para o tratamento dado aos funcionários comprometidos de modo integral com os objetivos da empresa (BEKIN, 2004, p.03).

Outras duas ferramentas de comunicação com o publico interno são o coaching e o aconselhamento, tipos de comunicação individualizada, para Williams (2017) a primeira diz respeito ao acompanhamento com cada funcionário com o proposito de melhorar seu desempenho ou comportamento na organização, já o aconselhamento diz respeito a questões não relacionadas ao trabalho como, por exemplo, a saúde do trabalhador e de seus familiares, ambas ferramentas, estão 
sendo usadas com frequência e promovem resultados satisfatórios tanto para os indivíduos quanto para as organizações.

Também existem vários outros meios e ferramentas estratégicas que promovem uma comunicação eficaz junto aos públicos de interesse, cabendo destacar segundo Hitt, Miller e Colella (2007) as seguintes:

- Auditorias na comunicação: analisar periodicamente auditorias na comunicação interna externa, visando avaliar as praticas e habilidades de comunicação para determinação de necessidades, essas auditorias podem ser realizadas tanto por membros internos da organização quanto por agentes externos.

- Culturas voltadas para a comunicação: para superação de barreiras pode-se estabelecer uma cultura dentro da organização que visa a promoção de canais de comunicação permanentes onde as pessoas devem estar compreensíveis para a implementação dessa cultura.

- Ações individuais: para melhorias na comunicação interpessoal, especialistas recomendam certas praticas como da escuta ativa, empatia, reflexão e feedback.

Ademais outras ferramentas podem ser utilizadas para melhorar a comunicação nas organizações, seja qual for a adotada, ela deve vir junto com a coerência e comprometimento interno em transmitir os reais valores da organização. Todos os elementos apresentados possuem efetivo destaque na construção de uma comunicação eficaz como os diversos stakeholders organizacionais, existem mais elementos, todavia o presente estudo se ateve àqueles mais presentes na literatura.

\section{METODOLOGIA}

A abordagem do problema nessa pesquisa é classificada segundo Sampieri, Collado e Lucio (2013) como enfoque qualitativo, pois se guia por áreas ou temas significativos da pesquisa, diferentemente do enfoque quantitativo onde esse se baseia em outros estudos anteriores, já o qualitativo se fundamenta primordialmente em si mesmo; estando em consonância com seus objetivos que é explorar e descrever o assunto que vai ser investigado.

A investigação qualitativa emprega diferentes alegações de conhecimento, estratégias de investigação e métodos de coleta e análise de dados. Embora os processos sejam similares, os procedimentos qualitativos se baseiam em dados de texto e imagem, têm passos únicos na análise de dados e usam estratégias diversas de investigação. (CRESWELL, 2007, p.184).

Os procedimentos adotados para resolução do problema são a pesquisa bibliográfica e a documental que segundo Gil (2010) apresentam muitos pontos de semelhança, a pesquisa bibliográfica depende de muitos fatores, tais como a natureza do problema, o nível de conhecimentos que o pesquisador dispõe sobre o assunto, o grau de precisão que se pretende conferir à pesquisa etc., já a pesquisa documental geralmente é descritiva ou explicativa, 
requerendo, portanto, um problema mais claro, preciso e especifico.

Ainda sobre a pesquisa bibliográfica que segundo Vergara (2009), é o estudo com base em publicações acessíveis ao publico geral como livros, revistas, jornais, redes eletrônicas, podendo ser fontes primarias ou secundarias, já Marconi e Lakatos (2008), coloca o pesquisador em contato direto com toda a bibliografia e material do assunto em questão, não é repetição, mas sim transcrever o que já existe de publicado com outro olhar, gerando um material novo.

A análise de dados no processo qualitativo de Sampieri, Collado e Lucio (2013) diz que os documentos servem para que o pesquisador conheça os antecedentes de um ambiente, as experiências, vivencias ou situações e como é o seu dia-a-dia, Gil (2010) acrescenta que a analise e interpretação de dados na pesquisa documental tende a variar conforme a natureza dos documentos utilizados. Para essa pesquisa foi utilizada vasta bibliografia, sendo verificados sempre elementos como a fidedignidade das informações, buscando acervos conhecidos e reconhecidos.

\section{ANALISE E DISCUSSÃO DE RESULTADOS}

Nesta seção verifica-se o resultado de toda a presente produção cientifica, tendo como referencia a pergunta de investigação e os objetivos estabelecidos, alinhado com a metodologia traçada, segue a analise e discussão dos resultados.

Os conceitos acerca da comunicação foram buscados em livros da área de administração, psicologia e propaganda e marketing, o quadro abaixo mostra a relação entre o autor e o conceito verificado.

\section{Quadro 1: Relação Autor x Conceito}

\begin{tabular}{|l|l|}
\hline AUTOR & CONCEITO COMUNICAÇÃO ORGANIZACIONAL \\
\hline $\begin{array}{l}\text { Bueno } \\
(2009)\end{array}$ & $\begin{array}{l}\text { Assim entendemos Comunicação empresarial, ou Comunicação } \\
\text { Organizacional como: Conjunto integrado de ações, estratégias, } \\
\text { planos, políticas e produtos planejados e desenvolvidos por uma } \\
\text { organização para estabelecer a relação permanente e sistemática } \\
\text { com todos os seus públicos de interesse. }\end{array}$ \\
\hline $\begin{array}{l}\text { Leavitt } \\
(1972)\end{array}$ & $\begin{array}{l}\text { Comunicação é um canal que influencia e permite trocas, sendo } \\
\text { necessária sua discussão pela criticidade que a mesma possui no } \\
\text { contexto organizacional. }\end{array}$ \\
\hline $\begin{array}{l}\text { Chiavenato } \\
(2014)\end{array}$ & $\begin{array}{l}\text { A comunicação é tornar algo comum, além disso, ele afirma que a } \\
\text { mesma permeia todas as funções administrativas, constituindo uma } \\
\text { parte essencial em cada atividade administrativa, é impossível } \\
\text { planejar, dirigir, organizar e controlar sem exercer a comunicação. }\end{array}$ \\
\hline $\begin{array}{l}\text { Carvalho e Serafim } \\
(1995)\end{array}$ & $\begin{array}{l}\text { A comunicação tem como característica a transmissão de ideias, } \\
\text { com finalidade de integrar por completo um grupo de trabalho. }\end{array}$ \\
\hline $\begin{array}{l}\text { Paulo Nassar } \\
(1995)\end{array}$ & $\begin{array}{l}\text { Ela não pode ser considerada apenas uma definçção de dicionário, } \\
\text { ou seja, simplesmente como um conjunto de métodos e técnicas de } \\
\text { comunicação dentro da empresa dirigida ao público interno } \\
\text { (funcionários) e ao público externo (clientes, fornecedores, } \\
\text { consumidores, etc.). }\end{array}$ \\
\hline
\end{tabular}


Cahen

(1990)
A comunicação é como uma atividade estratégica e sistêmica, pois está ligada ao planejamento estratégico organizacional, tendo como objetivos a criação, manutenção ou alteração da imagem da organização perante seu publico prioritário.

\section{Fonte: Elaborado pelo autor}

Os conceitos acima, alguns parafraseados, refletem o entendimento dos autores de que a comunicação organizacional é um processo, que visa transmissão de ideias no mundo corporativo com alcance a todos os públicos de interesse.

A teoria da gestão dos stakeholders possui uma abordagem muito recente, tendo como quadro abaixo alguns dos conceitos abordados e trazidos neste trabalho:

\section{Quadro 2: Relação Autor x Abordagem}

\begin{tabular}{|l|l|}
\hline AUTOR & ABORDAGEM DA GESTÃO DE STAKEHOLDERS \\
\hline $\begin{array}{l}\text { Rocha } \\
\text { (2010) }\end{array}$ & $\begin{array}{l}\text { Busca ampliar o foco da organização, que antes era satisfazer o } \\
\text { acionista e passa a ser satisfazer seus públicos de interesse } \\
\text { estratégicos, como clientes, funcionários, imprensa, parceiros, } \\
\text { fornecedores, concorrentes, sindicatos e a comunidade local. }\end{array}$ \\
\hline $\begin{array}{l}\text { Orth } \\
(2009)\end{array}$ & $\begin{array}{l}\text { Os stakeholders são pessoas, grupos de pessoas ou entidades que } \\
\text { participam ou influenciam o projeto, de maneira direta ou indireta, } \\
\text { com interesses em sua evolução ou quando são afetadas por seus } \\
\text { resultados de alguma maneira, sendo, portanto uma rede de } \\
\text { relacionamento, não necessariamente tendo interesses econômicos. }\end{array}$ \\
\hline $\begin{array}{l}\text { Williams } \\
(2017)\end{array}$ & $\begin{array}{l}\text { Stakeholders são pessoas ou grupos com um interesse legitimo em } \\
\text { uma empresa. Como são afetados pelas operações da organização, } \\
\text { os stakeholders tem interesses nelas. }\end{array}$ \\
\hline $\begin{array}{l}\text { Hitt, } \begin{array}{l}\text { Ireland } \\
(2008)\end{array} \\
\text { eskisson }\end{array}$ & $\begin{array}{l}\text { Stakeholders são pessoas e/ou grupos que podem afetar e são } \\
\text { afetados pelos resultados estratégicos obtidos e que tem } \\
\text { reivindicações aplicáveis no tocante ao desempenho da empresa. }\end{array}$ \\
$\begin{array}{l}\text { Chiavenato e Sapiro } \\
(2009)\end{array}$ & $\begin{array}{l}\text { Isso significa que a organização deve atender aos mínimos } \\
\text { interesses ou necessidades de todos os stakeholders, os quais } \\
\text { devem ser atendidos através das suas ações. Caso contrario, eles } \\
\text { podem decidir retirar seu apoio da organização e oferecê-lo a outra. }\end{array}$ \\
\hline
\end{tabular}

Fonte: Elaborado pelo autor

O principal objetivo da pesquisa é conhecer os elementos estratégicos utilizados pelas organizações no âmbito da comunicação com seus grupos de interesses, para isso, após as pesquisas realizadas no âmbito da literatura, chega-se aos seguintes resultados, demonstrado pela matriz abaixo: 
Figura 4: Matriz de relação comunicação com os Stakeholders

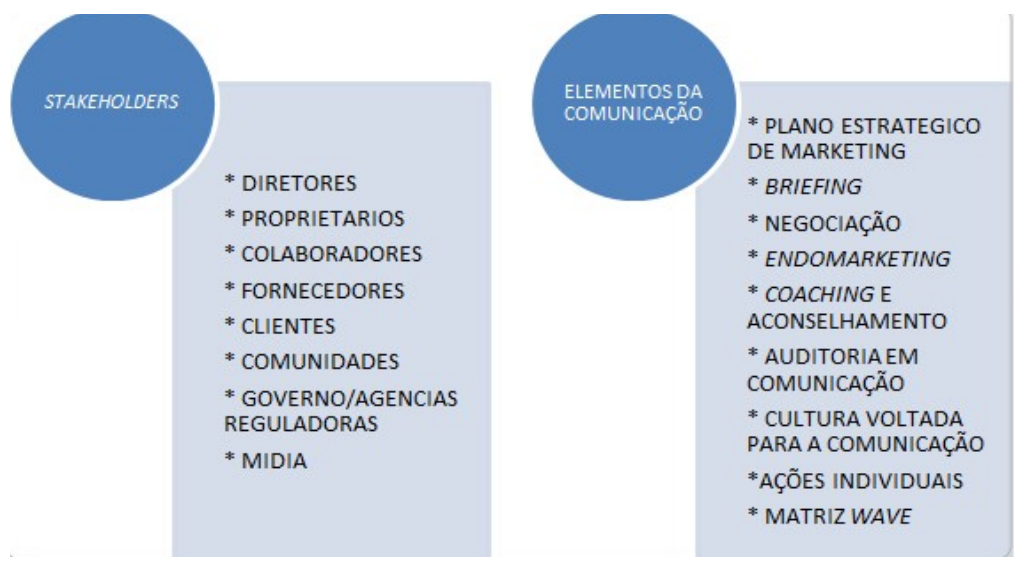

\section{Fonte: Elaborado pelo autor}

A matriz é uma demonstração gráfica que relaciona os itens apresentados, mostra primeiramente a organização ou a empresa, na escala acima são apontados os principais stakeholders encontrados nas organizações, e em seguida são apontados os elementos da comunicação mais vistos e utilizados no relacionamento com os públicos de interesses.

\section{CONSIDERAÇÕES FINAIS}

A presente pesquisa cujo objetivo foi descrever os elementos da comunicação que se alinham com os stakeholders das organizações evidenciou que os elementos mais discutidos na literatura possuem grande relevância para a estratégia organizacional, para chegar a tal conclusão, além de trazer conceitos diversos de comunicação organizacional foi feito um paralelo com a teoria da gestão de stakeholders.

Ao elencar os elementos da comunicação organizacional como o plano estratégico de comunicação, o briefing, a negociação, o endomarketing entre outros, não foi evidenciado a que publico de interesse os mesmos são voltados, isso porque alguns desses elementos podem fazer referencia a mais de um stakeholder, como por exemplo, a negociação que é voltada para os funcionários, mas também aos sindicatos, clientes e fornecedores, diferentemente do que ocorre com o endomarketing que é dirigido exclusivamente aos funcionários ou colaboradores. 
A preocupação maior na consecução da pesquisa foi quanto aos métodos utilizados, por ser uma pesquisa basicamente pura, onde apenas livros a subsidiaram, foi dado maior atenção ao tipo de publicação ou área de concentração e ao ano de publicação, por exemplo, para apresentar dados mais condizentes com a atualidade, houve prevalência de livros mais recentes, mas mesmo as obras mais antigas não foram desconsideradas, autores da década de setenta e noventa como Matos, Leavitt e Cahen tiveram destaque junto aos autores mais contemporâneos como Chiavenato, Rebouças e Rocha e Goldschimidt.

Tendo em vista os aspectos observados, constatou-se que a utilização das ferramentas da área da comunicação com os stakeholders, representa para além da estratégia da organização, é, sobretudo questão de sobrevivência, a utilização das mesmas deve ser eficiente a fim de evitar falhas e distorções neste processo, é preciso criar ambientes e canais de comunicação para cada stakeholder, que reflitam a realidade da organização.

Sob o enfoque da perspectiva estratégica, deu-se particular atenção aos processos relacionados ao planejamento, na construção de planos, programas e projetos, o planejamento é a primeira das funções administrativas, responsável por todas as ações das organizações, é preciso conhecer a organização e saber para onde a mesma quer seguir, mesmo que o cenário atual seja de profundas instabilidades e incertezas, deve-se partir do pressuposto que o planejamento é muito relevante, e que o mesmo também se admite mudanças, sua estaticidade, portanto é relativa.

O presente artigo traz também uma ferramenta muito interessante no planejamento da comunicação com os públicos de interesse, que é a Matriz Wave, a mesma é de fácil aplicação e utilização, ao planejar que tipo de comunicação será dado a cada stakeholder, têm-se maior noção do que está se fazendo e se é dada a devida importância em investimentos a cada publico de interesse; apesar de não ter sido mostrado um exemplo real de sua utilização, espera-se que outros trabalhos apliquem a Matriz Wave de forma mais didática, pois ela é sem duvida uma ferramenta útil e eficaz no contexto organizacional.

Em virtude do que foi mencionado, pode-se dizer que a comunicação organizacional é um dos mais importantes ativos da organização e que apesar disso, seu entendimento é muito complexo, mas mesmo assim é preciso dar o devido valor pra esse elemento e consequentemente haverá um melhor relacionamento com todos os stakeholders da organização. 


\section{REFERÊNCIAS}

BEKIN, Saul Faingaus. Endomarketing: Como praticá-lo com sucesso. São Paulo: Pearson Prentice Hall, 2004.

BERLO, David Kenneth. O Processo da comunicação: introdução à teoria e à prática. 10. Ed. São Paulo: Martins Fontes, 2003.

BOWDITCH, James L; BUONO, Anthony F. Elementos de comportamento organizacional. São Paulo: Pioneira, 1992.

BUENO, Wilson da Costa. Comunicação empresarial: políticas e estratégias. São Paulo: Saraiva, 2009.

CAHEN, Roger. Tudo que seus gurus não lhe contaram sobre comunicação empresarial. São Paulo: Best Seller, 1990.

CARVALHO, Antonio Vieira de. Administração de recursos humanos. v. 2. São Paulo: Cengage Learning, 1995.

CHIAVENATO, Idalberto. Administração nos novos tempos: os novos horizontes em administração. 3 Ed. Barueri, SP: Manole, 2014.

; SAPIRO, Arão. Planejamento estratégico. 2. Ed. Rio de Janeiro: Elsevier, 2009.

CORRADO, Frank M. A Força da Comunicação. São Paulo: Makron Books, 1994.

CRESWELL, John W. Projeto de pesquisa: métodos qualitativo, quantitativo e misto. Tradução Luciana de Oliveira da Rocha. - 2. ed. - Porto Alegre: Artmed, 2007.

FERREIRA, Aurélio Buarque de Holanda. Dicionário Aurélio. Rio de Janeiro: Nova Fronteira, 1986.

FRANÇA, Ana. C.L.; Praticas de Recursos Humanos - PRH: conceitos, ferramentas e procedimentos. 1. Ed. São Paulo: Atlas, 2014.

GIL, Antonio Carlos. Como elaborar projetos de pesquisa. 5. Ed. São Paulo: Atlas, 2010.

. Gestão de pessoas: enfoque nos papéis profissionais. São Paulo: Atlas, 2001.

HAMPTON, David R.; Administração contemporânea: teoria, pratica e casos. 3. Ed. São Paulo: Pearson Makron Books, 1992.

HITT, Michael A.; IRELAND, R. Duane; HOSKISSON, Robert E. Administração estratégica: competitividade e globalização. 2. Ed. São Paulo: Cengage Learning, 2008.

HITT, Michael A.; MILlER, C. Chet; COLELLA, Adrienne. Comportamento organizacional: uma abordagem estratégica. Rio de Janeiro: LTC, 2007. 
KAPPLAN, Robert S.; NORTON, David P. A estratégia em ação: balanced scorecard. Rio de Janeiro: Elsevier, 1997.

LEAVITT, Harold J. . Direção de empresas: psicologia de empresas de administração e chefia. Rio de Janeiro: Fundo de Cultura, 1972.

MARCHIORI, M. Cultura e comunicação organizacional. 2.ed. São Caetano do Sul: Difusão, 2008.

MARCONI, Marina de Andrade; LAKATOS, Eva Maria. Técnicas de pesquisa: planejamento e execução de pesquisas, amostragens e técnicas de pesquisa, elaboração, análise e interpretação de dados. 7. ed. São Paulo: Atlas, 2008.

MARQUES DE MELO, José. Comunicação Social: teoria e pesquisa. 4. ed. Petrópolis: Vozes, 1975.

MATOS, Francisco Gomes de. Gerência participativa: como obter a cooperação espontânea da equipe de desburocratizar a empresa. Rio de Janeiro: Biblioteca do Exército, 1980.

MAXIMIANO, Antonio Cesar Amaru. Introdução à administração. 6. ed. São Paulo: Atlas, 2004.

OLIVEIRA, Djalma de Pinho Rebouças de. Administração estratégica na prática: a competitividade para administrar o futuro das empresas. 5. Ed. São Paulo: Atlas, 2007.

ORTH, Afonso I. Planejamento e gerência de projetos. Porto Alegre: EDIPUCRS, 2009.

NASSAR, Paulo. Tudo é comunicação. São Paulo: Lazuli, 2006.

; FIGUEIREDO, Rubens. O que é comunicação empresarial. São Paulo: Brasiliense 1995.

PAZZIANOTTO, Almir. Negociação: reflexões e críticas. Salvador: Casa da Qualidade, 1995.

PENTEADO, J. R. W. A Técnica da Comunicação Humana. 8. ed. São Paulo: Livraria Pioneira Editora, 1982.

PEREIRA, Carlos Alberto Messeder; HERSCHMANN, Micael. Comunicação e novas estratégias organizacionais na era da informação e do conhecimento. Comunicação \& Sociedade, São Bernardo do Campo, 2. sem. 2002.

PIMENTA, M. A. Comunicação Empresarial. Campinas: Ed. Alínea, Campinas, 2004.

ROBBINS, Stephen P.; JUDGE, Timothy A.; SOBRAL, Filipe. Comportamento organizacional: teoria e prática no contexto brasileiro. 14. Ed. São Paulo: Pearson Prentice Hall, 2011.

ROCHA, Thelma; GOLDSCHMIDT, Andrea. Gestão dos Stakeholders: como gerenciar o relacionamento e a comunicação entre a empresa e seus públicos de interesse. São Paulo: Saraiva, 2010.

SAMPIERI, Roberto Hernández; COLLADO, Fernandes Carlos; LÚCIO, Pilar Baptista. Metodologia de pesquisa. 5. ed. Porto Alegre: Penso, 2013. 
SANT'ANNA, Armando; JÚNIOR, Ismael R.; GARCIA, Luiz F. D. Propaganda: teoria, técnica e prática. 8. Ed. São Paulo: Cengage Learning, 2009.

SCHULER, Maria. Comunicação estratégica. São Paulo: Atlas, 2004.

TAVARES, Mauricio. Comunicação Empresarial e planos de comunicação: integrando teoria e pratica. 2. Ed. São Paulo: Atlas, 2009.

VASCONCELOS, Luciene Ricciotti. Planejamento de Comunicação Integrada: manual de sobrevivência para as organizações do século XXI. São Paulo: Summus, 2009.

VERGARA, Sylvia Constant. Projetos e relatórios de pesquisa em administração. 11. Ed. São Paulo: Atlas, 2009.

WILLIAMS, Chuck. ADM: princípios de administração. 2. Ed. São Paulo: Cengage, 2017.

ZARIFIAN, Phillippe. Objetivo competência: por uma nova lógica. São Paulo: Atlas, 2008.

Recebido em: 20/08/2019

Aceito em: 10/09/2019

Endereço para correspondência:

Nome Manoel Henrique Ribeiro Castro*

e-mail: manoel_400@hotmail.com

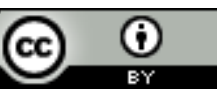

Esta obra está licenciada sob uma Licença Creative Commons Attribution 3.0 